\title{
Linguística Sistêmico-Funcional e suas contribuições à pesquisa linguística no contexto brasileiro ${ }^{1}$
}

\section{Systemic Functional Linguistics and its contributions to linguistic research in the Brazilian context}

\author{
Orlando Vian Junior \\ orlando.ufrn@gmail.com \\ Universidade Federal de São Paulo \\ Maria Medianeira de Souza ${ }^{* *}$ \\ medianeirasouza@yahoo.com.br \\ Universidade Federal de Pernambuco
}

\begin{abstract}
RESUMO: O objetivo deste texto é discutir, a partir da experiência dos pesquisadores no campo, as pesquisas em Linguística Sistêmico-Funcional em dois contextos no Nordeste brasileiro e como estas têm contribuído para a pesquisa linguística no cenário mais amplo do país. São descritos tanto estudos no âmbito dos contextos de cultura (gênero) e de situação (registro), quanto no âmbito dos estratos lexicogramatical e semântico-discursivo. Adota-se a perspectiva da "linguística do consumidor" (HALLIDAY, 1964, 1994; MARTIN, 1998; GOUVEIA, 2006; O'DONNELL, 2011) para discutir trabalhos relativos a gêneros acadêmicos e outros gêneros do discurso, à constituição da oração e do complexo oracional, ao sistema de avaliatividade, ao ensino de línguas e à formação de professores. Os resultados apontam para a produtividade das pesquisas no contexto e, como aponta Martin (1998), tem colocado a teoria à prova e renovado ou ampliado resultados de pesquisas anteriores.
\end{abstract}

PALAVRAS-CHAVE: Linguística Sistêmico-Funcional. Pesquisa. Gêneros discursivos. Lexicogramática. Semântica discursiva.

ABSTRACT: This text aims to discuss, from the experience of the researchers in the field, samples of research in Systemic-Functional Linguistics in two contexts in the Brazilian Northeast region and how they have contributed to the linguistic research in the broader scenario of the country. We describe both studies within the contexts of culture (genre) and situation (register), as well as within the lexicogramatical and discourse semantics strata. The perspective of a "consumer linguistics" (HALLIDAY, 1964, 1994; MARTIN, 1998; GOUVEIA, 2006; O'DONNELL, 2011) is used to discuss works related to academic genres and other discourse genres, to the constitution of the clause complex, the appraisal system, the teaching of languages and teacher

\footnotetext{
${ }^{1}$ Este texto congrega contribuições dos dois autores à mesa-redonda 3: Contribuições da LSF à pesquisa linguística no IV Simpósio Internacional de Linguística Funcional, realizado na Universidade Federal do Rio Grande do Norte, em Natal, de 31/05 a 02/06/17.

Doutor em Linguística Aplicada e Estudos da Linguagem pela Pontifícia Universidade Católica de São Paulo, Professor Associado da Universidade Federal de São Paulo

Professora Associada do Programa de Pós-graduação em Letras da Universidade Federal de Pernambuco.
} 
education. The results point to the productivity of the research in the context and, as Martin (1998) points out, how theory has been put on the line and renovated or expanded results from previous research.

KEYWORDS: Systemic Functional Linguistics. Research. Speech genres. Lexicogrammar. Discourse semantics.

\section{Introdução: contribuições da LSF à pesquisa no contexto brasileiro}

A partir da década de 1980, a Linguística Sistêmico-Funcional (LSF) passou a fazer parte do cenário em estudos linguísticos no Brasil, embora tenha uma longa jornada, principalmente com base no trabalho de Halliday e sua disseminação a partir da Universidade de Sydney, para onde ele se deslocou na década de 1970, e daí para o resto do mundo, com pesquisas em diversas línguas.

Em nosso país, os primeiros centros de pesquisa a desenvolverem trabalhos na área foram a Universidade Federal da Santa Catarina (UFSC), Pontifícia Universidade Católica de São Paulo (PUC-SP) e a Universidade Federal de Minas Gerais (UFMG) e, a partir de sua inserção nos programas de pós-graduação dessas universidades, passou a formar pesquisadores hoje atuantes nas cinco regiões do país e ampliando os estudos na área. Outro marco importante foi a criação da Associação de Linguística Sistêmico-Funcional da América Latina (ALSFAL), em 10 de abril de 2004, em Mendoza, na Argentina, como parte da First Latin American Regional Conference on SFL. A ALSFAL congrega pesquisadores dos diferentes países da América Latina e promove o intercâmbio entre pesquisadores de outras partes do mundo.

A LSF passou a ser presença constante nos diferentes eventos da área de Linguística e Linguística Aplicada no Brasil, bem como de Educação. E, por sua característica eminentemente interdisciplinar, de diálogo com outras teorias para explicação de fenômenos linguísticos, a LSF dialoga com áreas como Análise de Discurso Crítica, Gramática do Design Visual, Multimodalidade, Sociologia, Antropologia, Letramentos, Estudos de tradução, Linguística de corpus, Formação de professores, Audiodescrição, Educação/Pedagogia, dentre outras.

Uma das primeiras referências publicadas no Brasil sobre Sistema de Transitividade é o trabalho de Cunha e Souza $(2007,2011)$. As autoras abordam os contextos de uso do sistema a partir de duas perspectivas teóricas: a Linguística Funcional norte-americana e a Linguística Sistêmico-Funcional. Outro marco da 
pesquisa em LSF no Brasil é o trabalho de Fuzer e Cabral (2014), com o objetivo de auxiliar "estudantes de graduação em Letras, professores de língua portuguesa não iniciados na área e demais interessados nesta incursão aos estudos gramaticais sob um enfoque alternativo à gramática tradicional (FUZER; CABRAL, 2014, p. 14).

A partir dessas breves considerações, este texto tem por objetivo apresentar algumas contribuições da LSF para a pesquisa linguística no cenário brasileiro. Em função da nossa prática com ensino, pesquisa e extensão na área, focamos especificamente nas produções realizadas nos estados do Rio Grande do Norte e do Pernambuco, onde atuamos.

A motivação para o trabalho é traçar um breve panorama do que tem sido feito em LSF em contextos de pesquisa. Como forma de atingir o objetivo proposto, almejamos responder à seguinte pergunta de pesquisa: como a LSF pode contribuir à pesquisa linguística no contexto brasileiro? Este texto, portanto, estrutura-se para que essa questão seja respondida e, para tal, após as breves considerações sobre a pesquisa no cenário brasileiro e o histórico da LSF no Brasil, focaremos em nossas experiências. Tomamos por base ainda a noção de "linguística do consumidor", proposta por Halliday (1964) e subsequentemente, retomada por outros pesquisadores como Martin (1998), Gouveia (2006) e O'Donnell (2011). Em seguida, apresentamos pesquisas por nós desenvolvidas sobre diferentes práticas textuais em nossos contextos. Tecemos, por fim, algumas considerações sobre como tais contribuições podem concorrer para os estudos linguísticos e como pode fornecer subsídios para estudos futuros na área e fomentar a pesquisa no campo.

\section{Considerações acerca de uma "linguística do consumidor"}

Nosso percurso para a discussão de como a LSF tem oferecido possibilidades de pesquisa para compreensão de distintas práticas sociais em diferentes cenários socioculturais em nosso país parte da adoção do princípio de uma "linguística do consumidor", como proposta por Halliday (1964) e, posteriormente, revisitada e ampliada por outros pesquisadores, como apresentamos a seguir.

Halliday afirma que o "valor de uma teoria reside no uso que se pode fazer dela" ${ }^{2}$ e ressalta que, em seu trajeto para a elaboração de um arcabouço funcional

\footnotetext{
${ }^{2}$ Para evitar o excesso de notas com os trechos em língua inglesa, informamos que os trechos dos originais em inglês foram por nós traduzidos e são de nossa responsabilidade.
} 
para a linguagem, sempre pensou "que uma teoria de linguagem devesse ser essencialmente direcionada ao consumidor" (HALLIDAY, 1994, p. 7).

Consideremos o surgimento de uma perspectiva funcional, já que, na história da linguística ocidental, o percurso seguido geralmente pressupunha:

...primeiro as formas de palavras foram estudadas (morfologia); então, para explicar a forma das palavras, os gramáticos exploraram as formas das frases (sintaxe); e uma vez que as formas tinham sido estabelecidas, a pergunta era então colocada: "o que significam essas formas?" (HALLIDAY, 1994, p. x).

Em uma perspectiva funcional, como é apontado por Halliday (1994, p. x), “a direção é invertida. Uma linguagem é interpretada como um sistema de significados, acompanhado de formas através das quais os significados podem ser realizados". Assim, a questão a ser respondida diz respeito ao modo "como são expressados esses significados".

A compreensão de como os significados são expressados, desse modo, vai prescindir dos contextos em que os textos são produzidos e, aqui, é extremamente relevante compreender a maneira como a gramática sistêmico-funcional é arquitetada teoricamente, com três traços essenciais: (1) há uma relação dialética entre a língua e o contexto em que é produzida. O contexto abrange um contexto de cultura (gênero) e um contexto de situação (registro); (2) a língua apresenta-se organizada para uso em três estratos: o grafofonológico, o lexicogramatical e o semântico-discursivo; (3) três metafunções estão presentes em qualquer ocorrência de comunicação: ideacional, já que ideias, pensamentos, sentimentos e toda sorte de emoções são expressadas; interpessoal, uma vez que essas expressões ocorrem na interação com outros e textual, pois tudo que é expresso é organizado em texto. A essas metafunções estão subjacentes sistemas que realizam as ocorrências gramaticais da língua: o sistema de transitividade, subjacente à metafunção ideacional, o sistema de modalidade, à interpessoal e o sistema de tema, para a metafunção textual.

Essa perspectiva metafuncional e estratificada, finalmente, permite que compreendamos o porquê de uma linguística do consumidor. Nas palavras do próprio Halliday (2006, p. 19):

Eu sempre tentei trabalhar com uma orientação funcional para a 
linguagem; não evitando a teoria, porque sem a teoria não pode haver uma prática consistente e eficaz, mas tratando uma teoria como uma empresa de resolução de problemas e tentando desenvolver uma abordagem teórica e um modelo teórico da linguagem, que pode ser levado a exercer atividades cotidianas $\mathrm{E}$ tarefas. Chamo isso de linguística "appliable", mais appliable do que applicable, porque a palavra "applicable" refere-se a um propósito particular, enquanto "appliable" significa possuir a propriedade geral que pode ser usada em diferentes contextos operacionais.

A ideia semeada por Halliday (2006) acerca de uma orientação funcional para a linguagem e uma linguística que se imbui na tarefa de resolver problemas do cotidiano no que diz respeito à linguagem e seus usos em contextos é retomada por Martin (1998), em um contexto de mudanças na educação australiana. Em 2006, Gouveia volta a utilizar o conceito para discutir a questão de uma linguística do consumidor no contexto português, objetivando questionar a investigação linguística naquele país (GOUVEIA, 2006, p. 427). O'Donnell se reapropria do conceito em 2011 e o utiliza para discutir o papel de uma linguística do consumidor e o papel da LSF no ensino de inglês como língua estrangeira.

Essas diferentes perspectivas temporais e aplicadas sobre uma linguística do consumidor mostram a sua relevância e seu papel nos estudos linguísticos, apontando ainda para o nosso papel como linguistas e a relação de nossas pesquisas com os contextos em que estamos inseridos.

Os estudos em LSF em diferentes partes do mundo e as tentativas de descrição de idiomas diversos têm feito surgir tentativas de levar a cabo estudos que atendam às necessidades do consumidor, como é o caso do Martin Center for Appliable Linguistics, na Shanghai Jiao Tong University, na China, que promove os Appliable Linguistics Seminars.

Embora no Brasil não tenhamos adotado até recentemente a nomenclatura de uma "linguística do consumidor", as produções na área revelam a preocupação fulcral de entender as práticas sociais a partir de uma perspectiva gramatical, textual, linguística ou discursiva.

A "linguística do consumidor", em suma, pode ser compreendida como um arcabouço teórico por meio do qual as questões relacionadas à linguagem são exploradas a partir de seus distintos estratos (grafofonológico, lexicogramatical ou semântico-discursivo) e a partir de diferentes perspectivas metafuncionais (ideacional, interpessoal, textual), a depender das questões de pesquisa e também da área em que se insere o/a pesquisador/a no campo de estudos da linguagem, 
indo desde a linguística teórica e descritiva, à linguística aplicada e às demais teorias que estudam a linguagem. A LSF fornece instrumentos teóricos e metodológicos para análises de tais práticas.

Esse aspecto é reforçado por Mahboob e Knight (2010, p. 1) no prefácio de uma coletânea de trabalhos que adotam a "linguística do consumidor" como parâmetro:

\begin{abstract}
A linguística do consumidor é uma abordagem à linguagem que toma como ponto de partida problemas teóricos e práticos da vida real tanto teóricos como práticos - em diversos contextos sociais, profissionais e acadêmicos como ponto de partida e então desenvolve e contribui para um modelo teórico de linguagem que pode responder ao contexto e é aplicável a ele.
\end{abstract}

Tomando-se, desse modo, essas diversas possibilidades de utilizar os estudos linguísticos como um poderoso instrumento para a compreensão das práticas sociais que podem servir, posteriormente, para movimentos de intervenção, tais como formação de professores e profissionais de outras áreas para os quais a linguagem tem papel essencial, elencamos, a seguir, algumas experiências com base em nossa vivência como pesquisadores, atuando em universidades do Nordeste brasileiro.

\title{
2 Contribuições da LSF à pesquisa linguística
}

Com base nos pressupostos teóricos da LSF, a concepção de linguagem como metafuncional e estratificada tem guiado nossas pesquisas e nossas propostas de ensino, bem como a ideia de um ensino que tome por base os gêneros discursivos.

Os itens nesta seção, portanto, estão agrupados tanto a partir das possibilidades que a LSF fornece para análise das práticas textuais e seus contextos de produção e as distintas contribuições oferecidas, quanto a partir de nossa prática de ensino e pesquisa com base em seus princípios.

\subsection{Gêneros acadêmicos}

Sob a égide da LSF, faz-se obrigatória a análise de textos/gêneros em uso, realizando práticas sociais efetivas e, no caso do lócus acadêmico, é quase uma 
imposição do contexto que nosso foco como pesquisador recaia nos gêneros acadêmicos como objeto de investigação, seja porque constituem o nosso fazer na docência e na pesquisa, seja porque precisamos instrumentalizar nossos discentes nesse tipo de escrita. Investigar, portanto, a sua constituição nos estratos lexicogramatical e semântico-discursivo, sem sombra de dúvidas, logra aprendizagens no nível da compreensão e também da produção.

Por esse raio de pensamento e ação, nossas pesquisas em LSF, no âmbito da UFPE, até então, realizaram-se em dois gêneros acadêmicos: o artigo de graduandos e a dissertação de mestrado, ambos da produção de estudantes de Letras. Seja em nível de Iniciação Científica (maioria dos casos), seja em nível de pós-graduação, o aluno pesquisador necessariamente se volta sob sua prática de escrita acadêmica, simultaneamente ao seu trabalho como pesquisador, e essa via dupla reveste-se, assim, de significados.

Nos estudos empreendidos, norteavam nosso debruçar sobre os gêneros em apreço as seguintes concepções: (i) o artigo acadêmico é um dos primeiros gêneros textuais com os quais os graduandos têm contato ao ingressar na universidade, uma espécie de ensaio para o Trabalho de Conclusão de Curso (TCC), cujo objetivo consiste em apresentar sucintamente uma investigação acerca de um objeto, de um questionamento, ou em discutir ideias, métodos, projetos etc. já existentes, ou em contrastar obras diversas, como também em simplesmente fazer uma revisão de toda a literatura sobre determinado assunto. Sua finalidade é a divulgação em congressos, com a consequente busca de publicação em anais e/ou periódicos especializados (SALES, 2015); (ii) a dissertação, por sua vez, reflete a apresentação dos resultados de uma pesquisa mais elaborada, desenvolvida sob a orientação de um professor, acerca de um tema sobre o qual se devem apresentar e discutir provas, exemplos, argumentos, cujo propósito é a defesa de um ponto de vista, construído com base nos resultados obtidos, e apresentado por meio da utilização de diversos elementos argumentativos. São características de uma dissertação a capacidade de aplicação de um método de análise e a interpretação dos dados obtidos, no intuito de convencer o leitor sobre os resultados alcançados, com base em uma teoria já aceita, a partir da apresentação de provas que atestem o que está sendo levantado.

Com uma amostra significativa desses dois exemplares, realizamos investigações com foco no sistema de transitividade, especificamente nos processos 
verbais, que abriram veios para a observação do sistema de modalidade, pela modalidade presente nas orações constituídas com esse tipo de processo, e também para a averiguação do sistema de tema, quando essas orações assim se encontravam na posição de tema de um complexo oracional, o que ampliou o raio de investigação e consequentemente de entendimento da estrutura potencial desses gêneros. Somado a isso, o fato de que todas as análises envolviam os fraseados oracionais - texto como espécime (GOUVEIA, 2009) -, o contexto de situação e o contexto de cultura, apontamos os estudos de Penha (2011; 2015), Costa (2014), Silva (2015; 2016), Sales (2015; 2016), Souza e Mendes (2012; 2015) Souza, Sales e Silva (no prelo), embora com foco no construto oracional, como averiguações que resvalam na compreensão do gênero como artefacto (GOUVEIA, 2009) seja como leitor, seja como escritor e validam as propostas da LSF, razão pelas quais as percebemos como contribuições da LSF ao ensino-aprendizagem da escrita acadêmica.

As averiguações constituídas a partir da observação do uso dos sistemas retromencionados, em outras palavras, dos textos como janelas para o sistema, com foco específico na organização léxico-gramatical desses gêneros será a base para a descrição de nossa contribuição aos estudos em LSF no Brasil, no tocante à constituição da oração e do complexo oracional, conforme descrito no item 2.3.

Ainda inserido no contexto da universidade e no estudo dos gêneros acadêmicos, Vian Jr $(2011 ; 2014)$ enceta a discussão sobre o papel do artigo acadêmico na formação do pesquisador em linguística aplicada e sua relevância para um ensino focado nos gêneros que circulam nos contextos em que os produtores textuais estejam inseridos.

\subsection{Outros gêneros do discurso}

A análise de gêneros e a descrição de sua estrutura potencial revelam-se um importante instrumento não só para a compreensão das práticas sociais e como os textos que nelas circulam e organizam-se, mas também para o uso em práticas pedagógicas em que os gêneros sejam usados como objetos de ensino e, para tal, a compreensão da estrutura potencial bem como dos elementos linguísticos a eles característicos para o uso em diferentes contextos educacionais. 
Tomando-se a proposta de analisar gêneros, a pesquisa desenvolvida por Cooper (2012), além de descrever as estruturas do gênero "drama norte-riograndense", seus estágios e fases, também analisa os textos pela perspectiva dos sistemas discursivos da Avaliatividade e da Negociação (MARTIN; ROSE, 2007). Silva (2012), ao proceder à análise dos estágios e fases que compõem a estrutura potencial dos textos pertencentes ao gênero "histórias de ribeirinhos", com base em corpus gerado a partir de histórias contados pelos ribeirinhos às margens do rio Juruá, no estado do Acre, descreve, do ponto de vista linguístico, os sistemas discursivos de Ideação e de Periodicidade, a partir do mesmo escopo teórico do que propõem Martin e Rose (2007) para a análise de discurso de base sistêmicofuncional.

Propostas de estudos como essas contribuem de maneira significativa para a pesquisa linguística em LSF, não só a partir da ideia de gêneros discursivos e, portanto, a partir do contexto de cultura e do contexto de situação, mas também do estrato da semântica do discurso, donde emergem os princípios e procedimentos para uma análise de discurso de base sistêmico-funcional, conforme exposto no item 2.4.

\subsection{Constituição da oração e do complexo oracional}

Em pesquisa de doutoramento, Souza (2006) investiga o papel do sistema de transitividade na construção dos significados no gênero editorial, tomando a unidade máxima de análise lexicogramatical para a LSF, a oração, como lócus analítico, com vistas a compreender o funcionamento dos fraseados que permitiriam a realização do estrato semântico desse gênero e a consecução de seu objetivo, qual seja, defender um ponto de vista e conquistar a adesão do leitor.

Esse feito inicial guiou as pesquisas, desenvolvidas na sequência, no nível oracional, porém, tomando como objeto a escrita acadêmica, gêneros artigo e dissertação, para observar a oração organizada com processos verbais, compreendendo a relevância desse tipo de processo na tessitura dos gêneros em questão, uma vez que são eles os introdutores de vozes externas, as quais os discentes recorrem para referendar, embasar, explicar, situar, enfim, para argumentar e para legitimar sua voz como um autor iniciante na graduação, com os artigos, e, na pós-graduação, com a dissertação de mestrado. 
Nessa mesma direção, inserem-se os trabalhos de Penha (2011), Souza e Mendes (2012) e Costa (2012), que investigaram orações com processos verbais em artigos e dissertações, respectivamente. Penha (2011) faz um levantamento geral desse tipo de processo nos artigos, que constata o uso de 15 processos entre eles como: anunciar, sugerir, demandar, falar, informar, relatar, mas com destaque marcante para os verbos dizer e afirmar. Esses achados nortearam os estudos realizados posteriormente, razão pela qual Costa (2012) procede ao levantamento desses processos em dissertações de Linguística, cuja proposta subjacente seria também comparar os usos nos dois tipos de escrita.

Em termos quantitativos, os resultados são semelhantes e ratificam a disposição em investigar mais a fundo os verbos dizer e afirmar, uma vez que essas análises estavam inseridas em um projeto mais amplo do grupo SAL - Brasil, cujo foco consistia em analisar os processos verbais no português brasileiro em diversos gêneros. Essa participação no SAL também consolida a parceria com Mendes (2012) que analisa esses mesmos processos em trabalhos de graduandos em Letras, publicados em anais de eventos realizados na Universidade do Estado do Rio Grande do Norte.

Tais investigações tinham como propósito, além de identificar os processos verbais utilizados nos artigos acadêmicos de anais e da revista Ao Pé da Letra (nos três primeiros anos de publicação) e de dissertações em Linguística do Programa de Pós-Graduação em Letras da UFPE (em seus 30 anos de existência completados em 2008): (i) analisar o funcionamento dos processos verbais e seus participantes, Dizente, Verbiagem/Locução e Receptor, nos gêneros supramencionados; (ii) investigar as funções que esse tipo de processo, responsável por expressar o dizer, desempenha nesses gêneros. Esse procedimento tinha como orientação mais geral entender como se processava a construção da argumentação nos gêneros em análise através dos Processos verbais. Os resultados comprovam nossa assunção inicial e evidenciam o uso argumentativo das orações com processos verbais, seja introduzindo o discurso de outrem, seja introduzindo ditos dos próprios autores.

Por sua vez, as descrições minuciosas da organização oracional evidenciaram a presença da modalidade, dos vários tipos de grupo nominal Dizente, bem como do uso dessas orações em posição de Tema de complexos oracionais. Essas configurações abriram a porta para outros estudos na sequência desses, como por exemplo: Costa (2013) e Penha (2015) analisaram os efeitos da 
modalidade na argumentação da dissertação; por sua vez, Costa (2014) debruçouse sobre o grupo nominal e suas realizações lexicogramaticais na correlação formal com o semântico-discursivo. Saindo do nível da oração e adentrando na análise do complexo oracional, temos os estudos de Silva (2015) e de Sales (2015). Ambos averiguaram o funcionamento ideacional/textual de orações constituídas com os processos dizer e afirmar, atentando para seu duplo papel na organização do gênero, ou seja, como circunstância do sistema de transitividade, porém preenchendo a função de Tema do complexo oracional. Nessa linha de trabalho, apresenta-se também o capítulo de Souza e Mendes (2015).

Todas essas pesquisas apontam para a complexidade funcional dos fraseados analisados na escrita acadêmica e, sobretudo, corroboram a eficácia e relevância dos estudos sistêmico-funcionais e sua contribuição para o português brasileiro, porque não somente demonstram a coerência das categorias teóricoanalíticas dessa teoria como revelam as necessidades de adequações no aparato sistêmico-funcional em virtude das diferenças naturais entre os idiomas, em nosso caso, no português brasileiro.

\subsection{Sistema de Avaliatividade}

A abordagem de análise de discurso no âmbito da LSF prevê um conjunto de seis sistemas discursivos, conforme propõem Martin e Rose (2007). O Quadro 2, reproduzido de Vian Jr e Mendes (2015), objetiva apreender a relação entre os sistemas discursivos, no estrato da semântica do discurso, bem como suas funções, e como estão relacionados às metafunção, no estrato lexicogramatical, e suas funções:

Quadro 1: Relação sistemas discursivos/metafunções

\begin{tabular}{|c|c|c|c|}
\hline \multicolumn{2}{|c|}{ Sistema discursivo } & \multicolumn{2}{|l|}{ Metafunção } \\
\hline Identificação & $\begin{array}{l}\text { Rastrear pessoas e } \\
\text { coisas }\end{array}$ & \multirow[t]{2}{*}{ Textual } & \multirow[t]{2}{*}{ Organizar os textos } \\
\hline Periodicidade & Fluxo de informação & & \\
\hline Negociação & Promover trocas & \multirow{2}{*}{ Interpessoal } & \multirow{2}{*}{$\begin{array}{l}\text { Deflagrar relações } \\
\text { sociais }\end{array}$} \\
\hline Avaliatividade & Negociar atitudes & & \\
\hline Conjunção & Conectar eventos & \multirow[b]{2}{*}{ Ideacional } & \multirow[b]{2}{*}{$\begin{array}{l}\text { Representar a } \\
\text { experiência }\end{array}$} \\
\hline Ideação & $\begin{array}{l}\text { Representar a } \\
\text { experiência }\end{array}$ & & \\
\hline
\end{tabular}

Fonte: Vian Jr e Mendes (2015), com base em Martin e Rose ([2003]/2007) 
Fica explícita no Quadro 1 a relação entre os sistemas de Identificação e de Periodicidade e os significados na metafunção textual; os sistemas de Negociação e de Avaliatividade e a metafunção interpessoal, bem como os sistemas de Conjunção e Ideação e a metafunção Ideacional, tornando clara a relação entre estratos e os sentidos construídos em um e seu reflexo em outro.

Pelo fato de Martin e White (2005) terem publicado um amplo estudo sobre o sistema de avaliatividade, houve uma pletora de estudos focando nesse sistema e esse impacto ressoou no Brasil, com diversos estudos e publicações sobre o assunto.

O trabalho organizado por Vian Jr, Souza e Almeida (2010) apresenta perspectivas de análise a partir de diferentes prismas dos subsistemas para compreensão das relações sociais com base nos mecanismos de apreciação, julgamento e gradação, os três principais campos das avaliações humanas. Vian Jr (2009, 2012) também discutiu aspectos teóricos e metodológicos relacionados ao sistema.

Trabalhos como o de Aquino (2012) analisou como professores avaliam sua prática em uma sessão de visionamento, focando nos mecanismos de Atitude, e Vasconcelos (2013) observou os mecanismos de Apreciação, no âmbito do Sistema de Avaliatividade (MARTIN; WHITE, 2005), utilizados por alunos em um curso de inglês ao avaliarem sua produção oral.

Por seu foco nos mecanismos linguísticos utilizados para negociar atitudes, 0 Sistema de Avaliatividade traz contribuições substanciais para a compreensão das avaliações nos textos e a forma como se caracterizam léxico-gramaticalmente e semântico-discursivamente.

\subsection{Ensino de línguas}

Diversas são as propostas de inserção da Gramática Sistêmico-Funcional (GSF) no ensino de língua materna e também de línguas estrangeiras.

As propostas da Escola de Sydney para o ensino com base em gêneros têm uma sólida base no trabalho com a língua e, por essa razão, há diversas propostas não só de inserir aspectos pela perspectiva da LSF no ensino, mas também de compreender aspectos linguísticos de tais práticas. 
As indicações de Rose e Martin (2012) para o ensino de leitura e da escrita têm ressoado em diversas partes do mundo, assim como no Brasil. O trabalho de Vian Jr, Cooper e Uchoa (2015), por exemplo, discute a inserção de portfolios, podcasts e flash fiction no ensino de graduação. Ramalho (2013) analisa, pela perspectiva dos processos mentais do sistema de transitividade, as reflexões de alunos de licenciatura de Letras/Inglês por meio da análise de processos mentais nos portfólios produzidos como recurso avaliativo em uma disciplina de graduação.

No trabalho de Vasconcelos (2013), referido no item 2.4, embora utilize o Sistema de Avaliatividade como princípio de análise, os dados foram gerados a partir de um contexto em que alunos de inglês de um curso de idiomas avaliam suas percepções sobre o aprendizado da produção oral.

Essa pequena amostra revela possíveis modos de se usar a LSF no ensino de línguas, que devem ser considerados a partir do contexto em que se inserem. Devem ser levadas em conta, ainda, as necessidades do contexto e as perguntas das pesquisas.

\subsection{Formação de professores de língua inglesa}

A pesquisa em formação de professores é um campo que tem crescido a olhos vistos no Brasil. Prova disso é o Grupo de Trabalho na ANPOLL e, derivado desse grupo, o Congresso Latino Americano de Formação de Professores de Língua (CLAFPL), em sua sexta edição, realizada em 2016. Diversos são os modos pelos quais se podem observar as práticas docentes e as trilhas possíveis na formação continuada de professores, mais especificamente, em nosso campo de atuação, o professor de línguas, tanto materna quanto estrangeiras.

Em nossa experiência, temos enveredado por caminhos que tentam compreender desde os mecanismos linguísticos usados por professores em seus discursos para falar de seu processo reflexivo e de sua prática, como para discutir suas identidades, ou o modo como professores em formação inicial concebem futuras práticas.

O trabalho de Aquino (2012), por exemplo, referido no item 2.4., discute as avaliações realizadas por uma professora de inglês em uma sessão de visionamento sobre sua aula. Vargas (2011) apresenta aspectos das identidades de professores de língua inglesa. Santos (2011) faz um percurso de modo a discutir como os 
portfolios podem ser usados na formação inicial do professor de inglês, e Queiroz (2012) aborda, pela perspectiva linguística dos pronomes, em nível lexicogramatical, e pelos papéis sociais, em nível semântico-discursivo, como alunos de Letras concebem mudanças de um currículo. Milanez (2014), por seu turno, discute como professores de inglês para fins específicos concebem sua prática pedagógica a partir de suas experiências vividas.

Tendo como meta a formação de professores de inglês em um curso de Letras, em suas aulas de prática de ensino, Uchoa (2014) discute a inserção do gênero "podcast educacional" nesse contexto. Com o fito de atingir esse objetivo, o autor utiliza a LSF na análise das narrativas de professores em formação sobre a didatização de podcasts para o ensino de inglês em um munícipio na floresta amazônica, no estado do Acre.

A pesquisa desenvolvida por Oliveira (2015) se propôs a analisar o que os participantes da pesquisa concebiam como "bom professor" em um curso de idiomas no âmbito da universidade, com vistas a compreender as práticas do contexto, bem como a fornecer subsídios para a formação dos futuros professores que atuariam no contexto.

Essas são apenas ilustrações de pesquisas realizadas em nosso contexto. São amplas as amostras de pesquisas no campo de formação de professores em outros centros de pesquisa espalhados pelo país e que focam em diferentes nuances da formação de acordo com os contextos e as experiências docentes neles praticadas.

Como ficou patente pelos trabalhos de pesquisa expostos nos itens de 2.1 a 2.6, nossa prática tem procurado atender às necessidades dos contextos em que atuamos e, do mesmo modo, apresentando ampliações da teoria e aplicações à língua portuguesa.

\section{Considerações finais}

Nosso principal objetivo neste texto de responder à pergunta sobre como a LSF pode contribuir à pesquisa linguística no contexto brasileiro revela todo o potencial teórico e metodológico que o arcabouço arquitetado por Halliday e subsequentemente desenvolvido por outros pesquisadores oferece ferramental poderoso para compreender como o significado é construído pela linguagem nas 
mais distintas práticas sociais.

Talvez o ponto mais relevante das pesquisas apresentadas traga à tona o modo como os aspectos teóricos e práticos da LSF tem sido ampliados por pesquisas posteriores, não somente estudando aspectos do português brasileiro e aspectos tipológicos da língua, mas, acima de tudo, e indo ao encontro do que sugere Martin (1998, p. 442), "colocando as teorias à prova e renovando-as ou substituindo-as" e questionando o nosso próprio trabalho, muitas vezes retomado e ampliado por trabalhos posteriores de pesquisadores sob nossa orientação, mas não perdendo de vista o fato de contribuírem com seus contextos de atuação, propondo soluções para aspectos das práticas de linguagem

Nosso percurso abarcou pesquisas desenvolvidas em nossos contextos de atuação e ampliadas ou reformuladas em pesquisas posteriores, mas ficam indicadas as diversas outras possibilidades que vêm sendo desenvolvidas em outros contextos e nossas propostas de uma cartografia desses estudos (Souza e Vian Jr, em preparação).

Essas contribuições bem como futuras propostas de inserção da LSF em práticas pedagógicas encontram respaldo no que sugerira Neves (2004, p. 25) em sua discussão sobre a gramática a ser ensinada na escola:

A chave para algum progresso é uma só: a inserção das propostas em bases desenvolvidas pela ciência linguística, respaldadas em princípios e em métodos que salvam do diletantismo e do amadorismo. Essa aplicação da ciência linguística à atuação escolar há de servir a ambas as partes: assim como é a circulação da teoria linguística que há de renovar o tratamento escolar da linguagem, da língua, da gramática, assim também uma renovação efetiva desse tratamento há de realimentar discussões teóricas que com felicidade se apliquem à condução escolar da reflexão da linguagem.

O que já houvera apontado Neves (2004) nos induz ainda à reflexão de que, para uma linguística que atenda às necessidades do consumidor que a ela recorre para solucionar suas questões de pesquisa, é necessário, como sugere Martin (1998, p. 442) "causar problemas". E, de acordo com o referido autor, "para causar problemas temos de pôr nossas teorias em risco e renová-las ou substituí-las até que façam o que queremos que elas façam". Para isso, é preciso ter em mente, ainda segundo o que preceitua Martin, que "temos de fazer mais do que persuadir os nossos colegas em linguística e educação, temos de aprender a gerir a mídia, 
burocratas e políticos também" (MARTIN, 1998, p. 442). Este nosso texto, portanto, fica sendo uma possível contribuição nessa direção...

\section{Referências}

AQUINO, M. L. A linguagem da reflexão de uma professora de língua inglesa: um estudo de caso sob a perspectiva do Sistema de Avaliatividade. Mestrado em Estudos da Linguagem. Universidade Federal do Rio Grande do Norte, 2012.

COOPER, J. S. O macrogênero "drama norte-rio-grandense": uma análise de gênero e de discurso sob a perspectiva da linguística sistêmico-funcional. Doutorado em Estudos da Linguagem. Universidade Federal do Rio Grande do Norte, 2012.

COSTA, J. M. F. da. O funcionamento dos verbos do dizer em dissertações de Letras. Relatório de Pesquisa: Iniciação Científica - Universidade Federal de Pernambuco. Recife, 2012.

COSTA, J. M. F. da. O dizente e o funcionamento dos processos verbais no gênero dissertação. Relatório de Pesquisa: Iniciação Científica - Universidade Federal de Pernambuco. Recife, 2013.

COSTA, J. M. F. da. Um estudo do participante dizente em associação com os processos verbais na escrita de dissertações. Relatório de Pesquisa: Iniciação Científica - Universidade Federal de Pernambuco. Recife, 2014.

CUNHA, M. A. F. da; SOUZA, M. M. de. Transitividade e seus contextos de uso. Rio de Janeiro: Lucerna, 2007.

CUNHA, M. A. F. da; SOUZA, M. M. de. Transitividade e seus contextos de uso. 2. ed. São Paulo: Cortez, 2011.

FUZER, C.; CABRAL, S. R. S. Introdução à gramática sistêmico-funcional em língua portuguesa. Campinas, SP: Mercado de Letras, 2014.

GOUVEIA, C. A. M. A linguística e o consumidor: teoria, política e política da teoria. Actas do XXI Encontro Nacional da Associação Portuguesa de Linguística. Lisboa: APL, 2006, p. 427-433.

- Texto e gramática: uma introdução à Linguística Sistêmico-Funcional. Matraga, Rio de Janeiro, v.16, n. 24, p. 13-47, 2009.

HALLIDAY, M. A. K. Syntax and the consumer. Monograph Series in Language \& Linguistics, 17. Washington D.C.: Georgetown Univeristy Press, p. 14-23, 1964.

An introduction to functional grammar. 2nd ed. London: Edward Arnold, 1994. Some theoretical considerations underlying the teaching of English in China. 
The Journal of English Studies, Chongqing, China, v. 4, p. 7-20, 2006.

MAHBOOB, A.; KNIGHT, N. K. (Eds.) Appliable linguistics. London; New York: Continuum, 2010.

MARTIN, J. R. Linguistics and the consumer: the practice of theory. Linguistics and Education, vol. 9, iss. 4, pp. 411-448, 1998.

MARTIN, J. R.; WHITE, P. The language of evaluation: Appraisal in English. New York: Palgrave Macmillan, 2005.

MARTIN J.R.; ROSE, D. Working with Discourse. Meaning Beyond the Clause. 2nd ed. London: Continuum, [2003] 2007.

MILANEZ, M.K. Histórias de professores universitários sobre ensinar inglês para fins específicos. Tese (Doutorado em Estudos da Linguagem/Linguística Aplicada), Universidade Federal do Rio Grande do Norte, Natal, 2014.

NEVES, M. H. de M. Que gramática estudar na escola? Norma e uso na Língua Portuguesa. São Paulo: Contexto, 2004.

O'DONNELL, M. Syntax and the consumer revisited: an SFL for EFL. Plenária no International Systemic Functional Linguistics Congress (ISFC). Universidade de Lisboa, 25-29 de julho de 2011.

OLIVEIRA, E.M. de. Representações de professores de inglês em formação inicial sobre o "bom professor". Dissertação (Mestrado em Estudos da Linguagem), Universidade Federal do Rio Grande do Norte, 2015.

PENHA, R. F. A transitividade dos verbos do dizer em artigos acadêmicos. Relatório de Pesquisa: Iniciação Científica.Universidade Federal de Pernambuco. Recife, 2011.

PENHA, R. F. Processos verbais dizer e afirmar no gênero acadêmico dissertação de mestrado. Dissertação (Mestrado em Letras). Programa de Pós-Graduação em Letras/UFPE, Recife, 2015.

QUEIROZ, R. N. "Eu pensei que ia sair daqui falando inglês" - Um estudo sistêmicofuncional sobre papéis sociais atribuídos por alunos de um curso de Letras/Inglês. Dissertação (Mestrado em Estudos da Linguagem). Universidade Federal do Rio Grande do Norte, Natal, 2012.

RAMALHO, H. A. Processos verbais em portfolios de professores de inglês em formação inicial. Relatório de Pesquisa: Iniciação Científica - Universidade Federal do Rio Grande do Norte, 2013.

ROSE, D.; MARTIN, J. R. Learning to write, reading to learn: genre, knowledge and pedagogy in the Sydney School. London: Equinox, 2012.

SALES, M. A. O processo de tematização com orações circunstanciais em artigos da Revista Ao Pé da Letra: em análise os verbos do Dizer. Relatório de Pesquisa: Iniciação Científica - Universidade Federal de Pernambuco. Recife, 2016. 
SALES, M. A. Processos de textualidade com orações circunstanciais temáticas em artigos de graduandos em Letras. Relatório de Pesquisa: Iniciação Científica. Universidade Federal de Pernambuco. Recife, 2015.

SANTOS, C. M. O portfólio na formação inicial do professor reflexivo de Inglês como língua estrangeira: uma análise sistêmico-funcional. Dissertação de Mestrado em Estudos da Linguagem. Universidade Federal do Rio Grande do Norte, 2011.

SILVA, M. G. da. Histórias orais de ribeirinhos do Rio Juruá: um estudo de gênero e discurso de base sistêmico-funcional.Tese (Doutorado em Estudos da Linguagem) Universidade Federal do Rio Grande do Norte, 2012.

SILVA, D. Orações Circunstanciais na construção da textualidade de dissertações de Letras. Relatório de Pesquisa: Iniciação Científica - Universidade Federal de Pernambuco. Recife, 2015.

SILVA, D. O processo de tematização com orações circunstanciais em dissertações de Letras: em análise os verbos do dizer. Relatório de Pesquisa: Iniciação Científica - Universidade Federal de Pernambuco. Recife, 2016.

SOUZA, M. M. de; SALES, M. A.; SILVA, D. Análise léxico-gramatical de orações circunstanciais temáticas em artigos e dissertações: um estudo sistêmico-funcional. Anais do XI Congresso da Associação de Linguística Sistêmico-Funcional da América Latina. UFSM/UNIFRA: Santa Maria/RS. No prelo.

SOUZA, M. M. de. Transitividade e construção de sentidos no gênero editorial. Pósgraduação em Letras: UFPE, Tese de doutorado, 2006.

SOUZA, M. M. de; MENDES, W. V. Tema ideacional, circunstâncias e textualidade. In: CUNHA, M. A. F. (Org.) A gramática da oração: diferentes olhares. Natal: EDUFRN, 2015, p. 193-215.

SOUZA, M. M. de; MENDES, W. V. Uma análise sistêmico-funcional do dizer em artigos científicos de graduandos. DELTA, São Paulo, v. 28, p.537-560, 2012.

UCHOA, J. M. S. Narrativas de professores em formação sobre a didatização de podcasts para o ensino de inglês na floresta. Tese (Doutorado em Estudos da Linguagem) - Universidade Federal do Rio Grande do Norte, Natal, 2014.

VARGAS, B. Q. Representações de professores de língua inglesa de Natal/RN: um estudo sistêmico-funcional. Dissertação (Mestrado em Estudos da Linguagem) Universidade Federal do Rio Grande do Norte, Natal, 2011.

VASCONCELOS, J. A. de. Apreciações de alunos de inglês sobre sua produção oral: um estudo com base no Sistema de Avaliatividade. Dissertação (Mestrado em Estudos da Linguagem). Universidade Federal do Rio Grande do Norte, Natal, 2013.

VIAN JR, O. O sistema de avaliatividade e os recursos para gradação em língua portuguesa: questões terminológicas e de instanciação. DELTA, v. 25, n. 1. p. 99129, 2009. 
. O artigo na família de gêneros acadêmicos: notas sobre aspectos tipológicos, topológicos e seu papel no ensino-aprendizagem de leitura In: BARBARA, L.; MOYANO, E. I. (Orgs.). Textos e linguagem acadêmica: explorações sistêmicofuncionais em espanhol e português ed. Campinas: Mercado de Letras, 2011, p. 6786. 128, 2012.

Avaliatividade, engajamento e valoração. Revista DELTA, v. 28, n. 1, p 105Gêneros do discurso no letramento acadêmico do pesquisador em Linguística Aplicada In: NASCIMENTO, E. L.; ROJO, R. Gêneros de texto/discurso e os desafios da contemporaneidade. Campinas, SP: Pontes, 2014, p. 213-234.

VIAN JR., O.; SOUZA, A. A.; ALMEIDA, F. S. D. P. (Orgs.). A linguagem da avaliação em língua portuguesa: Estudos sistêmico-funcionais com base no Sistema de Avaliatividade. São Carlos, SP: Pedro\&João, 2010.

VIAN JR., O.; MENDES, W. V. O sistema de conjunção em textos acadêmicos: os mecanismos de sequenciamento e de explicação. Letras, v. 50, p. 163-186, 2015.

VIAN JR., O.; COOPER, J. S.; UCHOA, J. M. S. Portfolios, Flash Fiction e Podcasts: a inserção de novos gêneros no ensino de inglês na universidade In: VIAN JR., O.; CASADO ALVES, M. P. (Orgs.). Práticas discursivas: olhares da Linguística Aplicada. Natal: Editora da UFRN, 2015, p. 85-114. 